\title{
The spectrum and outcome of paediatric traumatic brain injury in KwaZulu-Natal Province, South Africa has not changed over the last two decades
}

\author{
J J P Buitendag, ${ }^{1} \mathrm{MB}$ ChB; V Y Kong, ${ }^{1} \mathrm{MB}$ ChB, MSc, PhD, MRCS; J L Bruce, ${ }^{1} \mathrm{MB}$ ChB, FCS (SA); G L Laing, ${ }^{1} \mathrm{MB}$ ChB, MSc, PhD, FCS (SA); \\ D L Clarke, ${ }^{1,2} \mathrm{MB}$ ChB, MPhil, MBA, MSc, PhD; P Brysiewicz, ${ }^{3}$ BSocSc, MCur, PhD, BA \\ ${ }^{1}$ Pietermaritzburg Metropolitan Trauma Service, Department of Surgery, University of KwaZulu-Natal, Durban, South Africa
${ }^{2}$ Department of Surgery, Faculty of Health Sciences, University of the Witwatersrand, Johannesburg, South Africa
${ }^{3}$ School of Nursing and Public Health, College of Health Sciences, University of KwaZulu-Natal, Durban, South Africa
}

Corresponding author: J J P Buitendag(johan_buitendag@yahoo.com)

\begin{abstract}
Objectives. This retrospective review of a prospectively entered and maintained hybrid electronic trauma registry was intended to develop a comprehensive overview of traumatic brain injury (TBI) in children and adolescents and to compare it with previous audits from our local environment and from other developing world centres. All TBI patients admitted to hospital were included in this study. We reviewed the age, gender, outcomes, radiological findings and treatment of the patients.

Methods. All patients aged $\leq 18$ years old who were admitted by the Pietermaritzburg Metropolitan Trauma Service (PMTS) with TBI between December 2012 and December 2016 were included in this audit.

Results. During the 4 -year period under review, a total of 563 children and adolescents were treated for TBI by the PMTS. The median age was 6.4 years and $29 \%(n=165)$ were females. The mechanism of TBI was blunt trauma in $96 \%(n=544)$ of cases, with $4 \%$ ( $n=19)$ suffering penetrating trauma. The penetrating mechanisms included impalement by a cow horn and miscellaneous injuries due to saws, axes, barbed wire, spades, stones and knives. The blunt mechanisms included falls $(n=102)$, assaults $(n=108)$, collapse of a building $(n=28)$, bicyclerelated injury $(n=14)$, falling off a moving vehicle $(n=280)$, motor vehicle accident (MVA; $n=59)$, pedestrian vehicle accident (PVA; $n=183$ ) and animal-related injuries $(n=8)$. There were $454(80 \%)$ mild, $67(12 \%)$ moderate and $42(7 \%)$ severe cases of TBI. A total of 48 patients were admitted to the intensive care unit and 23 were admitted to the high care unit. Nine patients died. All the deaths were in the MVA and PVA group. The spectrum of TBI as diagnosed on computed tomography scans was nonspecific cerebral contusion $(n=92)$, depressed skull fracture $(n=70)$, sub-arachnoid haemorrhage $(n=60)$, extradural haemorrhage $(n=41)$, intracerebral haemorrhage $(n=19)$, free air $(n=19)$, subdural haemorrhage $(n=13)$, intraventricular haemorrhage $(n=9)$. A total of $62(11 \%)$ patients required surgery.

Conclusion. There is a significant burden of paediatric TBI in Pietermaritzburg. The majority of TBI was related to blunt trauma and assaults were very common. Although the short-term outcomes are good, the long-term consequences are poorly understood. Injury prevention programmes are needed to help reduce this burden of disease and a nationwide trauma registry is long overdue.
\end{abstract}

S Afr Med J 2017;107(9):777-780. DOI:10.7196/SAMJ.2017.v107i9.12394

Trauma, particularly traumatic brain injury (TBI), is increasingly recognised as a major global public health problem, which is on par with infectious diseases and cardiac disease. A public health problem demands a co-ordinated multi-faceted response from a diverse group of stakeholders. ${ }^{[1-10]}$ South Africa (SA) has successfully mounted such a response to the HIV/AIDS pandemic and has, within a decade, rolled back the situation from one of abysmal and apocalyptic proportions to the management of a widespread chronic disease like diabetes. Hopefully, with continued intervention and the potential development of a vaccine, HIV/AIDS may ultimately be consigned to the history books. This remarkable achievement was based on a solid knowledge base generated by numerous clinical audits that accurately described and quantified the situation as it existed in the field. However, globally it would appear that in contrast to other public health problems such as cardiac diseases and infectious diseases, TBI has not been subject to adequate investigation or surveillance. ${ }^{[1-18]}$ SA, with its excessive trauma burden, is typical in this regard. There is no national trauma registry to track the epidemic in general and there are only a handful of local reports and audits which document the situation as it pertains to TBI in SA ${ }^{[11-15]}$ In addition, there are specific vulnerable population groups such as women, children and adolescents which have been inadequately investigated. TBI is an epidemic that is largely ignored, despite being reported on. This is problematic as it is difficult to motivate politically for resources, programmes and legislation to address these problems without a solid knowledge base.

This study was a retrospective review of a prospectively entered and maintained hybrid electronic trauma registry, ${ }^{[16]}$ which aimed to describe the incidence and outcomes of TBI among children and adolescents so as to develop a comprehensive overview of TBI in this population and to compare it with previous audits from SA. ${ }^{[1-18]}$ It is hoped that this audit will provide useful data to the various stakeholders who need to come together to combat this neglected epidemic.

\section{Methods}

The city of Pietermaritzburg is the capital of KwaZulu-Natal Province (KZN) and is the largest city in the western half of KZN. Approximately 1 million people reside in the city. The Pietermaritzburg Metropolitan Trauma Service (PMTS) maintains a prospective digital registry, which captures data on all surgical admissions. All surgical patients who require admission or transfer to a higher level of care are entered 
into this database. This includes patients admitted for neurological observations and neurological protection, patients requiring urgent transfer to the neurosurgical unit, as well as those requiring longterm admission for rehabilitation. Approval to maintain the registry has been obtained from the Biomedical Research Ethics Committee (ref. nos BCA221/13 and BE 207/09 BREC) of the University of KwaZulu-Natal and from the Research Unit of the Department of Health. The digital registry is unique and has been discussed in the literature. ${ }^{[16]}$ The clerking medical staff enter the data into an electronic pre-prepared clerking sheet. This process is the clerking process for all new admissions so the clinical data are entered in real time. As the data are entered, they are directly incorporated into the registry. The completed pre-prepared clerking sheet is then printed and becomes the patient's clinical record. At operation and on discharge a similar process is followed. This system combines the functions of a medical registry and a medical record system. It also combines an electronic system with a paper-based system and has been called the Hybrid Electronic Medical Registry. The data entry is strictly quality controlled by the staff of the PMTS using a process of daily review and weekly morbidity and mortality meetings. ${ }^{[16]}$

All patients aged $\leq 18$ years, who were admitted with TBI during the period December 2012 to December 2016, were included in the audit. Basic demographic data, vital signs on arrival, physical examination findings and Glasgow Coma Scale (GCS) were recorded. In accordance with advanced trauma life support, the conventional severity of TBI grading based on GCS was used: mild (13 - 15), moderate $(9-12)$ and severe (3 - 8) TBI. Final clinical outcomes were reviewed and were recorded as either survival or death. In the event of patient survival, the best GCS on discharge was noted.

\section{Statistical analysis}

Data were entered into an Excel spreadsheet and analysed using Stata 13.0 (StataCorp, USA). We generated basic descriptive statistics to describe the cohort of patients. Continuous variables were summarised using mean and standard deviation (SD) values and median (interquartile range (IQR)) values were presented in cases where there was evidence of skewing or asymmetrical outliers. We attempted to analyse trends in admission related to the following variables: nature of injury, mortality rate, number of admissions annually, age, sex, and mechanism of injury.

\section{Results}

During the 4-year period under review, a total of 563 children and adolescents were treated for TBI by the PMTS. The median age was 6.4 years and $29 \%(n=165)$ were female. In $96 \%(n=544)$ of cases, the mechanism of TBI was blunt trauma, with $4 \%(n=19)$ sustaining penetrating trauma. The penetrating mechanisms included impalement with a cow horn, as well as injuries sustained by a saw, an axe, barbed wire, a spade, stones and knives. The blunt mechanisms included falls $(n=102)$, assaults $(n=108)$, collapse of a building $(n=28)$, bicycle-related injury $(n=14)$, fall off a moving vehicle $(n=280)$, motor vehicle accident (MVA; $n=59$ ), pedestrian vehicle accident (PVA; $n=183$ ) and animal-related $(n=8)$ injuries. The average age according to the mechanism of trauma is shown in Table 1 and Fig. 1. The breakdown of GCS on admission is shown in Table 2. Of the cases, $80 \%(n=454)$ were mild, $12 \%(n=67)$ were moderate, and $7 \%(n=42)$ were severe TBI cases. A total of 48 patients were admitted to the intensive care unit and 23 were admitted to the high care unit. Nine patients died. All the deaths were in the MVA and PVA group.

The spectrum of TBI as diagnosed on computed tomography scan (Fig. 1) was intracerebral contusion (this is a broad term and includes

\begin{tabular}{|c|c|}
\hline Mechanism & Age (years), median (IQR) \\
\hline CS & $3(0.2-10)$ \\
\hline Fall & $3(0.2-15)$ \\
\hline BAI & $5.5(3-10)$ \\
\hline $\mathrm{FFH}$ & $5.5(0-17)$ \\
\hline FDS & $7^{*}$ \\
\hline PVA & $6(0-17)$ \\
\hline FFMV & $8(2-16)$ \\
\hline MVA & $9(0-17)$ \\
\hline FFB & $11.5(8-16)$ \\
\hline Assault & $15(0-17)$ \\
\hline PI & $15(1-17)$ \\
\hline
\end{tabular}

\begin{tabular}{|c|c|c|c|}
\hline $\begin{array}{l}\text { GCS on } \\
\text { admission }\end{array}$ & $\begin{array}{l}\text { Total }(N=563), \\
n(\%)\end{array}$ & $\begin{array}{l}\text { Survived }(N=554), \\
n(\%)\end{array}$ & $\begin{array}{l}\operatorname{Died}(N=9), \\
n(\%)\end{array}$ \\
\hline$<4$ & $7(1.2)$ & $4(0.7)$ & $3(33.3)$ \\
\hline 5 & $9(1.6)$ & $7(1.3)$ & $2(22.2)$ \\
\hline 6 & $16(2.8)$ & $14(2.5)$ & $2(22.2)$ \\
\hline 7 & $5(0.9)$ & $5(0.9)$ & 0 \\
\hline 8 & $5(0.9)$ & $5(0.9)$ & 0 \\
\hline 9 & $18(3.2)$ & $18(3.3)$ & 0 \\
\hline 10 & $11(2.0)$ & $11(2.0)$ & 0 \\
\hline 11 & $20(3.6)$ & $18(3.3)$ & $2(22.2)$ \\
\hline 12 & $18(3.2)$ & $18(3.3)$ & 0 \\
\hline 13 & $17(3.0)$ & $17(3.0)$ & 0 \\
\hline 14 & $43(7.6)$ & $43(7.8)$ & 0 \\
\hline 15 & $394(70.0)$ & $394(71)$ & 0 \\
\hline
\end{tabular}

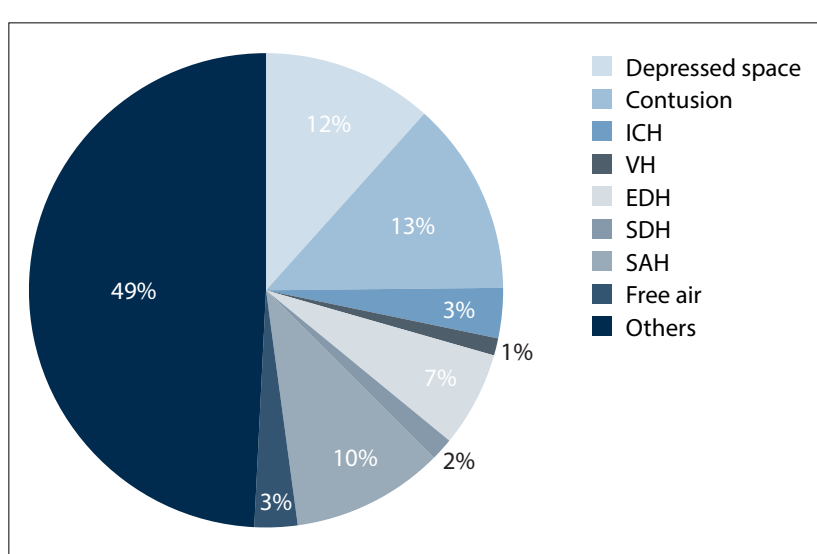

Fig. 1. Injuries sustained by the study population (\%). (ICH = intracerebral haemorrhage; $V H=$ ventricular haemorrhage; $E D H=$ extradural haemorrhage; $S D H=$ subdural haemorrhage; $S A H=$ sub-arachnoid haemorrhage.)

the frontal, parietal, temporal and occipital contusions) (13.0\%, $n=92)$, depressed skull fracture $(11.7 \%, n=70)$, sub-arachnoid haemorrhage $(10.4 \%, n=60)$, extradural haemorrhage $(6.5 \%, n=41)$, intracranial haemorrhage $(3.4 \%, n=19)$, free air $(2.9 \%, n=19)$, subdural haemorrhage $(1.5 \%, n=13)$, intraventricular haemorrhage $(1.1 \%, n=9)$. A total of $62(10.6 \%)$ patients required surgery and were referred to our neurosurgical centre. The operations needed 
included cranioplasty $(n=2)$, craniotomy ( $n=28)$, debridement $(n=3)$, decompressive craniotomy $(n=7)$, shunt $(n=2)$, and washout $(n=1)$.

\section{Discussion}

The centre in SA that has most consistently reported on paediatric TBI is the Red Cross War Memorial Children's Hospital in Cape Town. A series of reports over the last four decades reveal an epidemic of TBI in children which has been largely ignored. ${ }^{[9-14]}$ Table 3 compares the data from these studies. Our data were similar to those reported from these earlier SA studies. ${ }^{[9-14]}$ In keeping with these reports, the predominant mechanism of TBI in children was blunt trauma. However, the high incidence of assault as a mechanism of blunt trauma reflects the high level of interpersonal violence which is the norm in SA. ${ }^{[1-9]}$ There were different injury patterns according to age. Falls seem to occur in the age range of 6 - 8 -years-old. From the age of 11 years onwards, bicycle-related injuries become more common. The incidence of assault and penetrating trauma begins to increase in the older age groups as children approach adolescence and early adulthood (Table 1). The most common injuries are depressed skull fractures or intracerebral contusions, followed by sub-arachnoid haemorrhage. Discreet space-occupying lesions such as an extradural or subdural haematoma are less common. ${ }^{[1-8]}$ The need for neurosurgical intervention was low (3.4\%). Only a small subset of patients required formal neurosurgical intervention and the vast majority were managed by general surgeons and intensivists. The mortality rate was $3.6 \%$. The data from these series are remarkably similar to our current series and demonstrate that little has changed since the turn of the millennium in terms of paediatric TBI management in SA as a whole, and in KZN in particular.

In a recent global review, investigators evaluated 165000 children who had sustained a TBI across five continents. ${ }^{[9]}$ Our results are broadly in keeping with this global survey. As we have shown, there is a male predominance especially in children older than three. A bimodal age distribution is often described, with very young children $(0$ - 2 years $)$ and adolescents ${ }^{[16-19]}$ being more commonly injured. In our study, mild TBI (GCS $\geq 13$ ) constituted $>80 \%$ of injuries and only $\sim 10 \%$ of patients needed an operation. The major mechanisms of injury in children were falls and motor vehicle collisions. However, in the developing world children are more frequently pedestrian victims than passengers. Non-accidental trauma is a common cause of paediatric TBI in both the developing and developed world. Outcomes for TBI in children are by and large good..$^{[9,11-15]}$ Mortality was associated with low GCS on admission and was confined to the MVA and PVA cohorts. However, this gives a false sense of the severity of TBI. The effects of a TBI in a child may be long-term and may impact on the child's future ability to work and earn a salary.

\section{Study limitations}

The lack of a proper classification of the severity of the injury based on computed tomography scan findings ${ }^{[17]}$ was a limitation; however, it should provide an impetus for efforts to develop a nationwide trauma registry. ${ }^{[8,9]}$

\section{Conclusion}

One of the key components in the systematic response to trauma is the development of a trauma system with dedicated trauma centres. ${ }^{[18-20]}$ The huge burden of trauma in SA is overwhelming and requires a co-ordinated public health-based response. This response must combine curative efforts with prevention strategies. ${ }^{[1-9]}$ Primary prevention also needs to be emphasised. Based on this and other SA audits, we need to address the issues of vehiclerelated injuries and interpersonal trauma. Some risk factors can be addressed by improved vehicle safety as well as by the introduction of traffic calming zones around schools and public places. Dealing with the issue of intentional trauma in children is more challenging.

There is a significant burden of paediatric TBI in Pietermaritzburg. The majority of TBI was related to blunt trauma and assaults were very common. Although the short-term outcomes were good, the long-term consequences are still poorly understood. Despite a number of reports on TBI, the epidemic is largely ignored and prevention programmes are needed to help reduce this burden of disease. A nationwide trauma registry is long overdue.

Table 3. Comparative data from similar studies

\begin{tabular}{|c|c|c|c|c|c|c|c|c|}
\hline & $\begin{array}{l}\text { Present study } \\
\text { (Buitendag et al.) }\end{array}$ & $\begin{array}{l}\text { Kihurani } \\
\text { et al. }{ }^{[21]}\end{array}$ & $\begin{array}{l}\text { Schrieff } \\
\text { et al. }{ }^{[15]}\end{array}$ & $\begin{array}{l}\text { Okyere- } \\
\text { Dede } \\
\text { et al. }{ }^{[11]}\end{array}$ & $\begin{array}{l}\text { Lalloo and } \\
\operatorname{van} \mathbf{A s}^{[14]}\end{array}$ & $\begin{array}{l}\text { Semple } \\
\text { et al. }{ }^{[13]}\end{array}$ & $\begin{array}{l}\text { Kibel } \\
\text { et al. }{ }^{[22]}\end{array}$ & $\begin{array}{l}\text { Knobel } \\
\text { et al. }{ }^{[23]}\end{array}$ \\
\hline Year & 2017 & 2014 & 2013 & 2013 & 2004 & 1998 & 1990 & 1984 \\
\hline$N$ & 563 & 4690 & 137 & 506 & 37610 & 102 & 5468 & 1820 \\
\hline Age, median (years) & 6.4 & 6.3 & 6.1 & 6 & 4.9 & ND & 4.9 & ND \\
\hline Male (\%) & 71 & 63 & 65 & 65 & 59 & 56 & ND & 67 \\
\hline \multicolumn{9}{|l|}{ Cause of TBI (\%) } \\
\hline MVA & 10 & 28 & 21 & 63 & 6.5 & 0 & 11.4 & 48 \\
\hline PVA & 33 & 71 & 55 & 0 & 12.2 & 83 & 0 & 0 \\
\hline Assault & 19 & 0 & 0.7 & 23 & 13.1 & 0 & 0 & 8.5 \\
\hline Falls & 18 & 0 & 5 & 5 & 41.2 & 11 & 43.4 & 31 \\
\hline Other mechanisms & 20 & 1 & 18.3 & 9 & 27 & 6 & 45.2 & 12.5 \\
\hline \multicolumn{9}{|l|}{ Severity (\%) } \\
\hline Mild & 81 & 58 & ND & ND & ND & ND & ND & ND \\
\hline Moderate & 12 & 37 & ND & ND & ND & ND & ND & ND \\
\hline Severe & 7 & 5 & ND & ND & ND & 100 & ND & ND \\
\hline \multicolumn{9}{|l|}{ Outcome (\%) } \\
\hline Conservative management & 89 & 0 & 0 & 96 & 96.4 & 91.2 & 0 & 0 \\
\hline Surgical management & 11 & 0 & 0 & 4 & 3.6 & 8.8 & 0 & 0 \\
\hline Mortality & 1.5 & 0.6 & 14.6 & 3.6 & 0.2 & 57 & 0 & 4.2 \\
\hline
\end{tabular}




\section{Acknowledgments. None.}

Author contributions. JJPB analysed the data and wrote the manuscript. DLC analysed data and wrote the manuscript. VYK, JLB, GLL and PB reviewed the manuscript.

\section{Funding. None.}

Conflicts of Interest. None.

1. Muckart DJ. Trauma - the malignant epidemic. S Afr Med J 1991;79(2):93-95

2. Peden M, Butchart A. 1999, Trauma and injury. In: Crisp N, Ntuli A, eds. South African Health Review. Durban: Health Systems Trust, 1999:265-276.

3. Butchart A, Peden M, Matzopoulos R, et al. The South African national non-natural mortality surveillance system - rationale, pilot results and evaluation. S Afr Med J 2001;91(5):408-417.

4. Matzopoulos RG, Prinsloo M, Butchart A, Peden MM, Lombard CJ. Estimating the South African trauma caseload. Int J Inj Contr Saf Promot 2006;13(1):49-51 https://doi.org/10.1080/15660970500036382

5. Hardcastle TC, Samuels C, Muckart DJ. An assessment of the hospital disease burden and the facilities for the in-hospital care of trauma in Kwa-Zulu-Natal, South Africa. World J Surg 2013; 37(7):1550-1561. for the in-hospital care of trauma in Kwa-Z
https://doi.org/10.1007/s00268-012-1889-1

6. Moodley NB, Aldous C, Clarke DL. An audit of trauma-related mortality in a provincial capital in South Africa. S Afr J Surg 2014;2(4):101-104. https://doi.org/10.7196/sajs.1995

7. Manchev V, Bruce JL, Oosthuizen GV, Laing GL, Clarke DL. Spectrum of paediatric and adolescent trauma managed by the Pietermaritzburg Metropolitan Trauma Service. Ann R Coll Surg Engl 2015;97(4):274-278. https://doi.org/10.1308/003588414X14055925061595

8. Lutge E, Moodley N, Tefera A, Sartorius B, Hardcastle T, Clarke D. Hospital based surveillance system to assess the burden of trauma in KwaZulu-Natal Province South Africa. Injury 2016;47(1):135-140. https:// doi.org/10.1016/j.injury.2015.08.020

9. Dewan MC, Mummareddy N, Wellons JC 3rd, Bonfield CM. Epidemiology of global pediatric traumatic brain injury: Qualitative review. World Neurosurg 2016;91:497-509.el. https://doi.org/10.1016/j.
wneu.2016.03.045

10. Zulu BM, Mulaudzi TV, Madiba TE, Muckart DJ. Outcome of head injuries in general surgical units with an off-site neurosurgical service. Injury 2007;38(5):576-583. https://doi.org/10.1016/.jinjury.2007.01.002
11. Okyere-Dede EK, Nkalakata MC, Nkomo T, Hadley GP, Madiba TE. Paediatric head injuries in the KwaZulu-Natal Province of South Africa: A developing country perspective. Trop Doct 2013;43(1):1-4. https://doi.org/10.1177/0049475513480490

12. Peacock WJ. Head injuries in children. S Afr Med J 1984;66(21):789-790.

13. Semple PL, Bass DH, Peter JC. Severe head injury in children - a preventable but forgotten epidemic. S Afr Med J 1998;88(4):440-444.

14. Lalloo R, van As AB. Profile of children with head injuries treated at the trauma unit of Red Cross War Memorial Children's Hospital, 1991 - 2001. S Afr Med J 2004;94(7):544-556.

15. Schrieff LE, Thomas KG, Dollman AK, Rohlwink UK, Figaji AA. Profile of severe traumatic brain injury admissions to Red Cross War Memorial Children's Hospital, 2006 - 2011. S Afr Med J 2013;103(9):616620. https://doi.org/10.7196/samj.7137

16. Laing GL, Bruce JL, Skinner DL, Allorto NL, Clarke DL, Aldous C. Development, implementation and evaluation of a hybrid electronic medical record system specifically designed for a developing world surgical service. C World J Surg 2014;38(6):1388-1397. https://doi.org/10.1007//500268-013-2438-2.2.35

17. Marshall LF, Marshall SB, Klauber MR, et al. The diagnosis of head injury requires a classification based on computed axial tomography. J Neurotrauma 1992;9(Suppl 1):S287-S292.

18. Hardcastle TC, Finlayson M, van Heerden M, Johnson B, Samuel C, Muckart DJ. The prehospital burden of disease due to trauma in KwaZulu-Natal: The need for afrocentric trauma systems. World J Surg 2013;37(7):1513-1525. https://doi.org/10.1007/s00268-012-1852-1

19. Hardcastle TC, Steyn E, Boffard K, et al. Guideline for the assessment of trauma centres for South Africa. S Afr Med J 2011;101(3):189-194. https://doi.org/10.7196/samj.4682

20. Hardcastle T. The 11P's of an Afrocentric trauma system for South Africa - time for action! S Afr Med 2011;101(3):160-162

21. Kihurani I, Niekerk AV, van As AB. Child road traffic crash injuries at the Red Cross War Memorial Children's Hospital in Cape Town South Africa in 1992, 2002 and 2012. Int J Injury Cont Saf Promot 2014;22(4):352-358. https://doi.org/10.1080/17457300.2014.912236

22. Kibel SM, Bass DH, Cywes S. Five years' experiece of injured children. S Afr Med J 1990;78(7)387-391

23. Knobel GJ, de Villiers JC, Parry CD, Botha JL. The causes of non-natural deaths in children over a 15year period in greater Cape Town. S Afr Med J 1984;66(21):795-801. 